\title{
Prevention and management of diabetes and its complications by unani herbal medicine - a review
}

\begin{abstract}
Diabetes is one of the most important health problems today affecting 15 million of people worldwide. The prevalence of Diabetes in the world wide was estimated to be about $4 \%$ in 1995 and will rise to $5.4 \%$ by the year 2025. The number of adults with Diabetes in the world wills rise from 135 million in 1995 to 300 million by the year 2025. Nature has provided us a rich storehouse of herbal remedies to cure all aliments of mankind. India has vast and inexhaustible resources of drugs of plants origin. There has been resurgence in the consumption and demand for medicinal plants. These plants are finding use as pharmaceutical, nautraceuticals, cosmetic and food supplements. Even traditional source of medicine they continue to play a pivotal role. Plants have been source of medicine from ancient times for controlling blood sugar level. In this review article, an attempt has been made to compile the reported hypoglycemic plants as these drugs are also described in unani classical literature for prevention and management of diabetes mellitus and its complications.
\end{abstract}

Keywords: diabetes mellitus; complications; prevention; unani herbal medicine; management
Volume 4 Issue 4 - 2017

\author{
Mohammad Nasar K \\ Department of General Medicine, India
}

Correspondence: Mohammad Nasar K, Associate Professor, Department of General Medicine, Dr. Abdul Haq Unani Medical College, Kurnool, India Email drnasar.ahumc@gmail.com

Received: April II, 2017| Published: May 02, 2017

\section{Introduction}

Diabetes is a group of metabolic disorder characterized by Hyperglycemia resulting from defects in insulin secretion, its sensitivity or both World wide it affecting more than 300 million people. India has today become the Diabetic capital of the world with over 20 million diabetes and this number is yet too increased to 57 million by the year 2025 . Diabetes is ranked $7^{\text {th }}$ among the leading cause of death and is considered $3^{\text {rd }}$ when its fatal complications are taken into account. For this, therapies developed along the principles of conventional medicine are often carry the risk of adverse effects and are often expensive, especially for the developing world. Therefore, treating diabetes mellitus with plant derived compounds which are accessible easily. ${ }^{1-3}$

\section{Causes of diabetes mellitus}

Diabetes causes vary depending on genetic condition, family history, ethnicity, health and environmental factors. The causes of diabetes vary depending on the individual and the type. For instance; the causes of type 1 diabetes vary considerably from the causes of gestational diabetes. Similarly, the causes of type 2 diabetes are distinct from the causes of type 1 diabetes.

\section{Type I diabetes causes}

Type 1 diabetes is caused by the immune system destroying the cells in the pancreas that produces insulin. This causes diabetes by leaving the body without enough insulin to function normally. This is called an autoimmune reaction, or autoimmune cause. The following triggers may be involved: viral or bacterial infection, chemical toxins within food, unidentified component causing autoimmune reaction and underlying genetic disposition may also be a type 1 diabetes cause.

\section{Type 2 diabetes causes}

Type 2 diabetes causes are usually multifactorial more than one diabetes cause is involved. Often, the most overwhelming factor is a family history of type 2 diabetes. There are a variety of risk factors for type 2 diabetes, any or all of which increase the chances of developing the condition. These include: anxiety, stress, advance age, obesity, sedentary life style, irregular diet etc. Obesity has been found to contribute to approximately $55 \%$ type II diabetes and decreasing consumption of saturated fats. Diabetes is often initially managed by modifying the diet to limit and control glucose intake, and in consequence, blood glucose levels, is known to assist type 2 patients, especially early in the course of the condition's progression. Additionally, weight loss is recommended and is often helpful in patients suffering from type 2 diabetes

\section{Complications}

Long-term complications of diabetes include retinopathy with potential loss of vision Diabetic Retinopathy is leading cause of

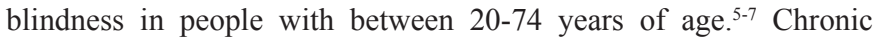
hyperglycemia results in multiple end stage organ damage and failure including the Heart, kidneys, eyes, nerves, blood vessels. Diabetes associated with cardiovascular complications are believed to be responsible for the high morbidity and mortality observed in Diabetes. ${ }^{4}$ There is increased incidence of atherosclerotic cardiovascular diseases and cerebro-vascular diseases, Hypertension and abnormality of lipoprotein metabolism are often found in people with Diabetes mellitus. ${ }^{8}$ Diabetic Nephropathy leading to renal failure, peripheral neuropathy with risk of foot ulcers, amputation and Charcot joint and Autonomic neuropathy is causing gastro-intestinal, genitor urinary and cardiovascular symptoms and sexual dysfunction. ${ }^{9}$ 


\section{Prevention}

The most important prevention measure in patients with diabetes is the diet. Sufferers need to monitor closely every food and every meal. There is a small effort to watch diet and to pay attention to everything eat, if compared with the fact that will be able to avoid a bunch of complications that turn diabetes into a very dangerous condition.

Diabetes complications can be prevented and even reversed. In most of the cases the patients needs a lot of will to accept the changes. The patient has to follow strict diet regime and systematic life style. Subsequently therapy which would activate the pancreas is also required.

\section{Management of diabetes millets by herbal medicine}

Diabetes in its early stages is curable by using Unani herbal medicine. Since antiquity, diabetes has been treated with plant medicines. Recent scientific investigation has confirmed the efficacy of many of these herbs, some of which are remarkably effective. Only those herbs that appear most effective are relatively non-toxic and have substantial documentation of efficacy are covered here.

Herbal medicines are being used by about $80 \%$ of the world population. The natural products are considered the best because of better acceptability, safety and efficacy, potency, inexpensive with least side effects. Several herbal medicines and supplements have been potential therapeutic agents in the management of Diabetes and its related complications. Given that over 800 plants are listed with anti diabetic potential and proven anti diabetic efficacy. Patients seem to demand more and more safe and effective medicinal compound to better manage diabetic complications. ${ }^{10-15}$

The Unani system of medicine is found very effective in treating chronic diseases related to respiratory, gastro-intestinal, cardiovascular, central nervous, dermatological, inflammatory disorders and diabetes especially. For instance there are some oils that can affect the hormonal balance in the body directly or indirectly. As a direct action, the oils work as phyto hormones in the same way as that an animal or human hormone would work on the body. The oils also act indirectly by triggering a particular gland into action or by balancing hormonal secretion in some way. Thus black pepper, fennel and juniper oils have a restoring and rejuvenating affect on the pancreas, while carrots, eucalyptus, geranium, lemon oils in inhalation, massage, bath or in the form of tea are insulin stimulants. Some medicinal plants such as dammul akhwain, karela, jamun, methi, pyaz, gurmar, darchini etc are documented in unani classical texts. ${ }^{15-19}$

\section{Dammul Akhwain (Pterocarpus marsupium Linn)}

The tree is the source of the Kino of the European pharmacopeas. The gum-resin looks like dried blood (Dragon's blood), much used in Indian medicine. This herb has a long history of use in India as a treatment for diabetes. The flavonoid, (-)-epicatechin, extracted from the bark of this plant has been shown to prevent alloxan-induced beta cell damage in rats.

Both epicatechin and a crude alcohol extract of Pterocarpus marsupium have actually been shown to regenerate functional pancreatic beta cells. No other drug or natural agent has been shown to generate this activity. ${ }^{11}$

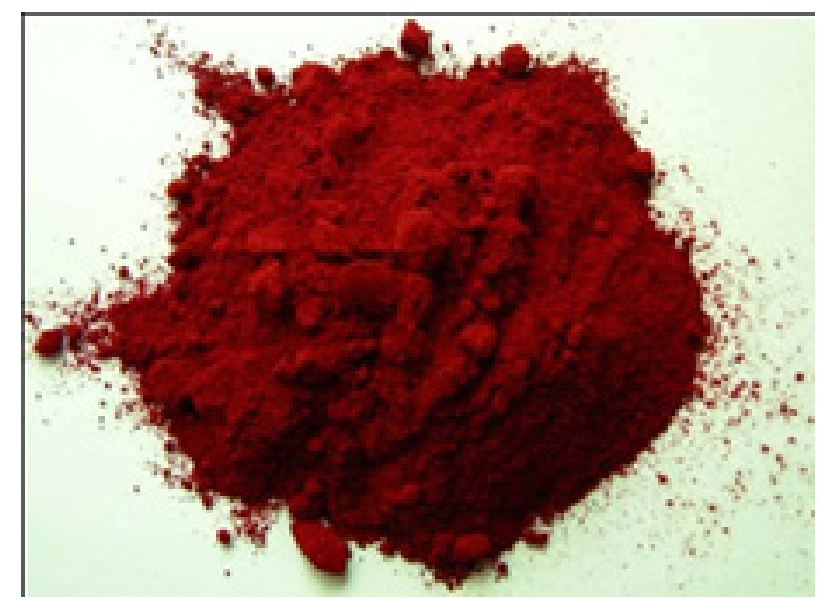

\section{Karela (Momordica charantia Linn)}

It is very popular for its anti-diabetic properties. It's also rich in micronutrients which are required for prevention of complications of diabetes. Bitter melon, also known as balsam pear, is a tropical vegetable widely cultivated in Asia, Africa and South America, and has been used extensively in folk medicine as a remedy for diabetes. The blood sugar lowering action of the fresh juice or extract of the unripe fruit has been clearly established in both experimental and clinical studies.

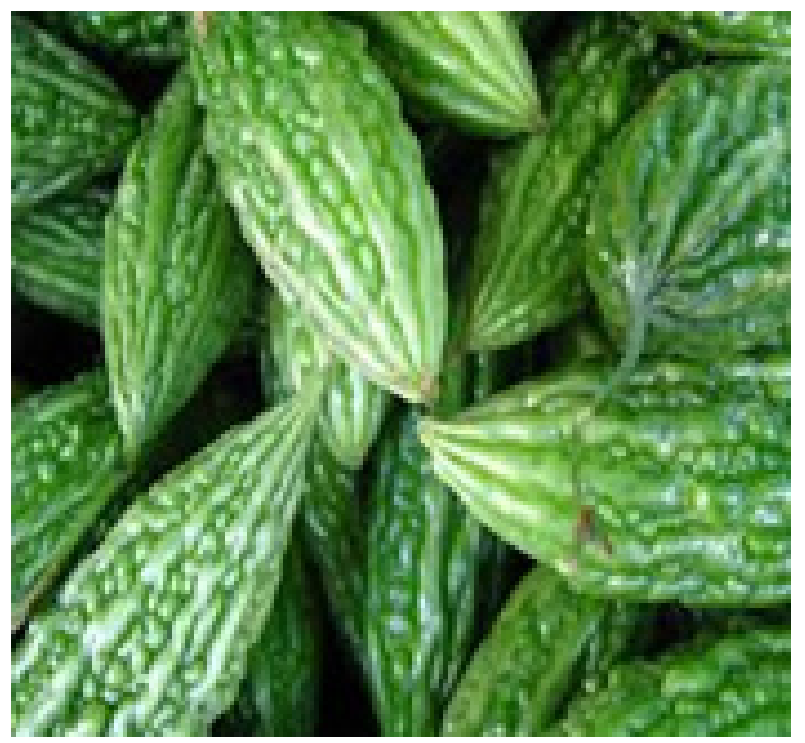

Bitter melon is composed of several compounds with confirmed anti-diabetic properties. Charantin, extracted by alcohol, is a hypoglycaemic agent composed of mixed steroids that is more potent than the drug tolbutamide which is often used in the treatment of diabetes. Momordica also contains an insulin-like polypeptide, polypeptide-P, which lowers blood sugar levels in type 1 diabetic patient. The oral administration of $50-60 \mathrm{ml}$ of the juice has shown good results in clinical trials. ${ }^{14}$

Excessively high doses of bitter melon juice can cause abdominal pain and diarrhea. Small children or anyone with hypoglycemia 
should not take bitter melon, since this herb could theoretically trigger or worsen low blood sugar, or hypoglycemia. Furthermore, diabetics taking hypoglycemic drugs (such as chlorpropamide, glyburide, or phenformin) or insulin should use bitter melon with caution, as it may potentiate the effectiveness of the drugs, leading to severe hypoglycemia. ${ }^{11,13}$

\section{Gurmar (Gymnema Sylvestre Linn)}

Gymnema assists the pancreas in the production of insulin in Type 2 diabetes. Gymnema also improves the ability of insulin to lower blood sugar in both Type 1 and Type 2 diabetes. It decreases cravings for sweet. This herb can be an excellent substitute for oral blood sugar-lowering drugs in Type 2 diabetes. Some people take $500 \mathrm{mg}$ per day of gymnema extract. ${ }^{20}$

\section{Pyazl Lehsan (Allium cepa Linn and Allium sativum Linn)}

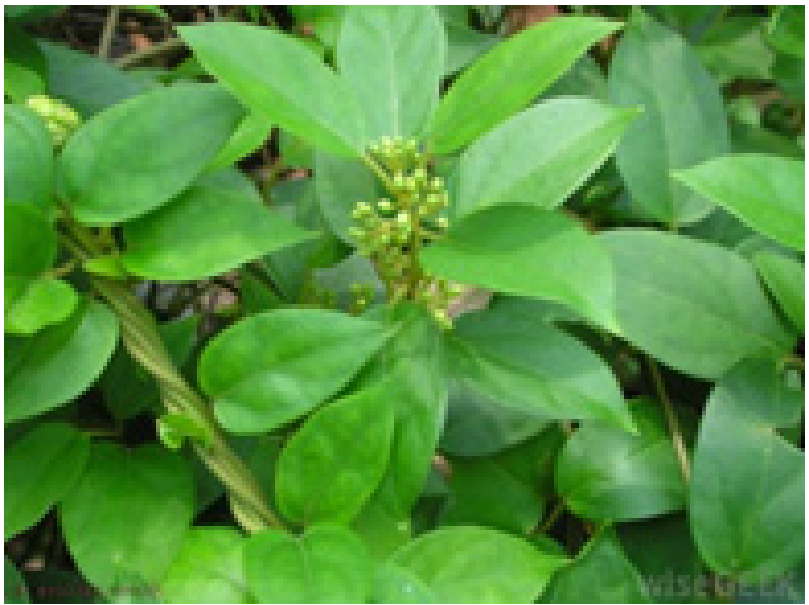

Onion and garlic have significant blood sugar lowering action. The principal active ingredients are believed to be allyl propyl disulphide (APDS) and diallyl disulphide oxide (allicin), although other constitutents such as flavonoids may play a role as well.

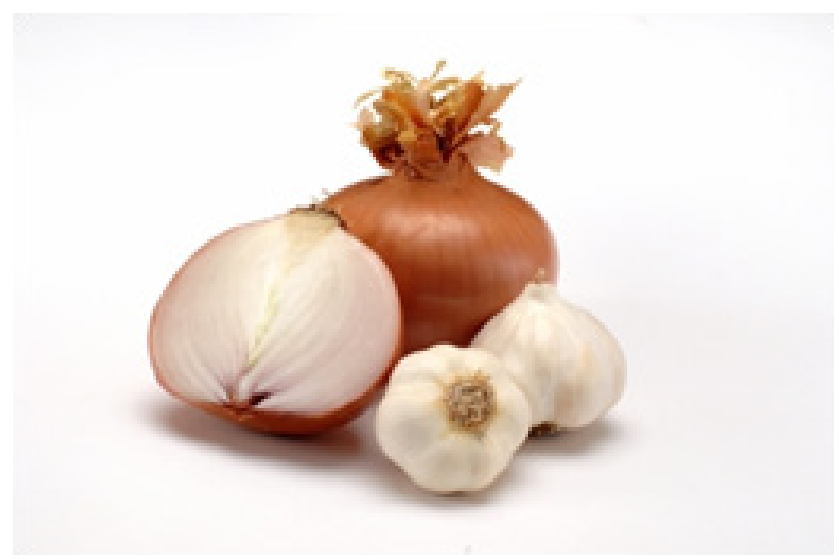

Experimental and clinical evidence suggests that APDS lowers glucose levels by competing with insulin for insulin-inactivating sites in the liver. This results in an increase of free insulin. APDS administered in doses of $125 \mathrm{mg} / \mathrm{kg}$ to fasting humans was found to cause a marked fall in blood glucose levels and an increase in serum insulin. Allicin doses of $100 \mathrm{mg} / \mathrm{kg}$ produced a similar effect. ${ }^{20,21}$
Onion extract was found to reduce blood sugar levels during oral and intravenous glucose tolerance. The effect improved as the dosage was increased; however, beneficial effects were observed even for low levels that used in the diet e.g. 25 to 200 grams. The effects were similar in both raw and boiled onion extracts. Onions affect the hepatic metabolism of glucose and/or increase the release of insulin and/or prevent insulin's destruction.

The additional benefit of the use of garlic and onions are their beneficial cardiovascular effects. They are found to lower lipid levels, inhibit platelet aggregation and are antihypertensive. So, liberal use of onion and garlic are recommended for diabetic patients.

\section{Methi (Trigonella foenum-graecum Linn)}

Experimental and clinical studies have demonstrated the antidiabetic properties of fenugreek seeds. The active ingredient for the antidiabetic properties of fenugreek is in the defatted portion of the seed that contains the alkaloid trogonelline, nicotinic acid and coumarin.

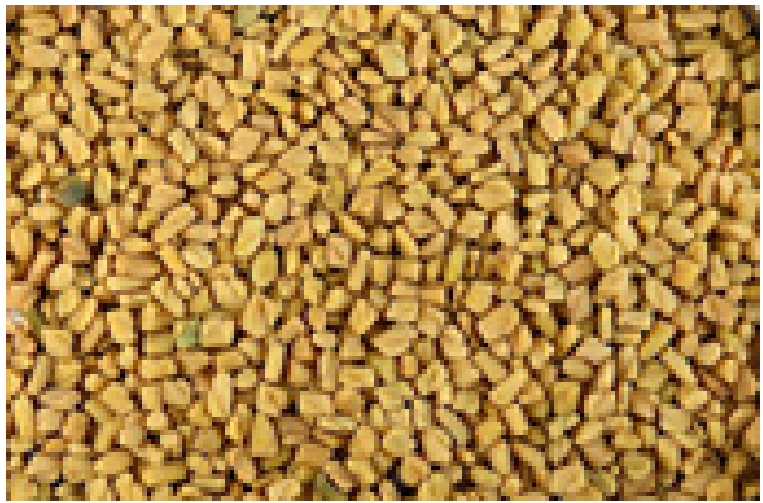

Fenugreek may help improve blood glucose levels in people with both Type 1 and Type 2 diabetes, according to several studies. In addition, this herbal diabetic treatment may also help improve blood cholesterol and triglyceride levels.

\section{Darchini (Cinnamon zylanicum Linn)}

Cinnamon comes from the inner bark of a tropical evergreen tree and has insulin-like properties. This herbal diabetic treatment can help lower blood glucose levels as well as cholesterol and triglycerides, and some studies suggest that cinnamon can help boost antioxidants in the body and may help reduce metabolic syndrome. ${ }^{18,19}$

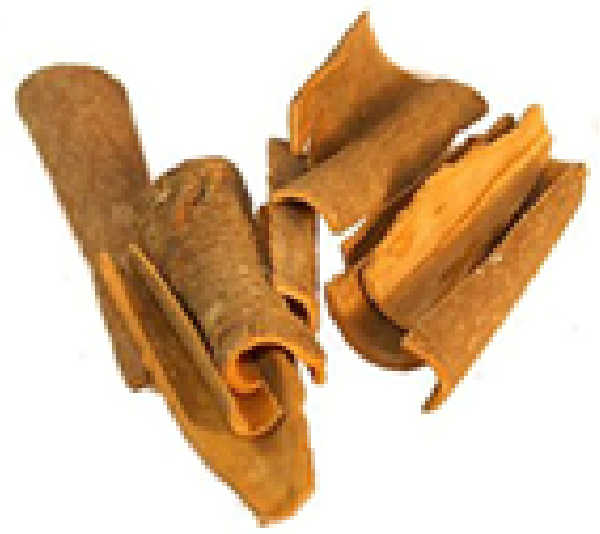




\section{Jamun (Eugenia Jambolana Linn)}

The fruit and seeds of the Jambul tree have long been used in Eastern traditional medicine. The extract of the jamun pulp showed hypoglycemic activity within 30 min of administration, while the seeds of the same fruit require $24 \mathrm{hrs}$. There was increase in serum insulin level and the extract also inhibited insulinase activity from liver and kidney. ${ }^{20}$

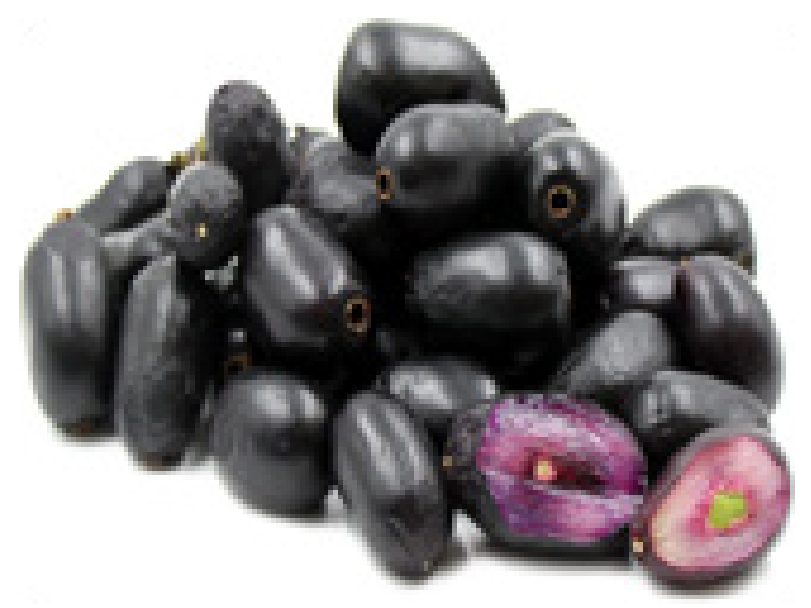

\section{Ghekwar (Aloe Vera)}

Aloe Vera is a popular houseplant, has a long history as a multipurpose folk remedy. The plant can be separated into two basic products: gel and latex. Aloe Vera gel is the leaf pulp or mucilage, aloe latex, commonly referred to as "aloe juice," is a bitter yellow exudate from the pericyclic tubules just beneath the outer skin of the leaves. Extracts of aloe gum effectively increases glucose tolerance in both normal and diabetics. ${ }^{21}$

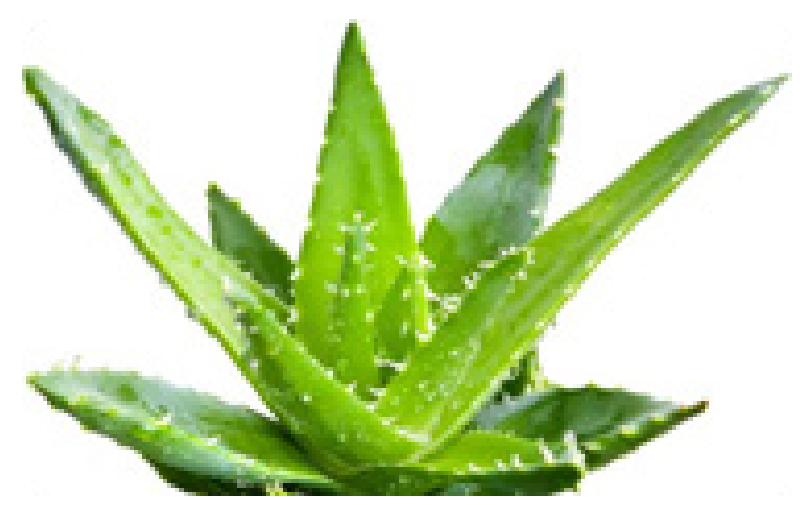

\section{Mango leaves ( Mangifera Indica Linn)}

Effect of leaves of mangifera India on Diabetic Nephropathy is good. It is significantly inhibited glomerulas extra cellular matrix expansion and accumulation and transforming growth factor- beta -1 over expansion in glomeruli of Diabetic Nephropathic patients. Mangiferin has an immune-stimulating effect on both cellular and hormonal immunity link. Mangiferin is a normal metabolite also to be found in mango leaves. In the Republic of Vietnam a technology has been elaborated, and subsequently improved, for obtaining Mangiferin from mango leaves Pharmacokinetics of Mangiferin in the blood after oral administration: A small amount of free Mangiferin is observed in the blood plasma after single use of Mangiferin at dose range between $50 \mathrm{mg} / \mathrm{kg}$ and $1000 \mathrm{mg} / \mathrm{kg}$. Plasma level of Mangiferin is not over $0.05 \mu \mathrm{g} / \mathrm{ml}$ over 24-hour follow-up. Mangiferin metabolite is not detected in the blood within 24 hours after oral administration. Excretion of free Mangiferin in the urine is not over $0.1 \%$ within 24 hours. $^{22}$

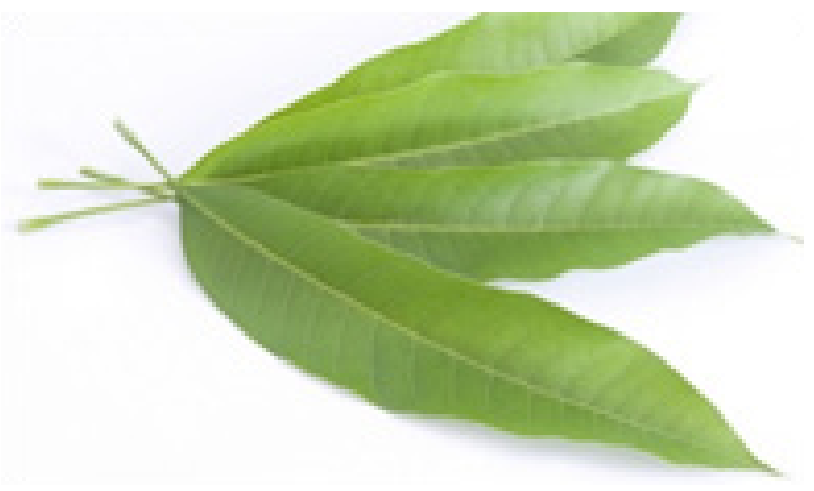

\section{Diet in diabetes}

Change in diet is the important factor in the management of diabetes. Eating right helps to keep blood sugar, blood lipids and blood pressure under control, which help from complication. Elimination of all simple carbohydrates and inclusion of a high fiber diet is desirable. The calorie content of the food is important in planning diet. High calorie food consumption leads gaining obesity, glucose intolerance, dyslipidemia, coronary artery disease, atherosclerosis etc. So, an ideal diabetic diet includes calorie content, glycemic index and physical form of food. The high carbohydrate, high fiber diet is highly recommended.

\section{Exercise and weight reducing in NIDDM}

Physical activity is an important factor in controlling blood sugar levels. Exercise can prevent the onset of NIDDM and it regulates the blood glucose for those already suffering from diabetes. Exercise promotes the entry of glucose into the cells thereby lowers blood sugar levels. Exercise also prevent cardiovascular disease, reduces cholesterol levels and weight.

\section{Conclusion}

Diabetes mellitus is a most common endocrine disorder, affecting more than 300 million people worldwide. Treating diabetes mellitus with plant derived compounds which can accessible easily. Plants have played a significant role in human health and life for thousand of year. Using herbal or natural medicines for the treatment of diabetes and its complications has a long and extensive history. All these herbal drugs discussed in this review exhibit significant clinical and pharmacological activities. The potency of herbal drugs is significant and they have negligible side effects. Supplementation of these herbal drugs for diabetic patients prevents the development of oxidative stress and its associated complication.

\section{Acknowledgements}

None.

\section{Conflicts of interest}

The author declares there is no conflict of interest. 


\section{References}

1. King H Aubert RE, Herman HW. Global burden of Diabetes Mellitus. Diabetic care. 1998;21:1414-1431.

2. World LE, Ceylan-Isik AF, Ren J. Oxidative stress and stress signaling: menace of diabetic cardiomyopathy. Acta Pharmacol Sin. 2005;26(8):908-917.

3. Lebovitz HE. Etiology and pathogenesis of diabetes mellitus. Pediatr Clin North Am. 1984;31(3):521-530.

4. Fein FS, Sonneubick EH. Diabetic cardio-myopathy. Prognosis of cardiovascular disease. 1985;27(14):255-270.

5. Klein R, Klein, $B E K$. Vision disorders in diabetes in Diabetes in America. National Diabetes Data Group (2 ${ }^{\text {nd }}$ edn), USA. 1995; pp. 293-338.

6. Rahi JS, Sripathi S, Gilbert CE, et al. Child hood blindness in India: Causes in 1318 blind school children in nine states. Eye (Lond). 1999;9( Pt 5):545-550.

7. Alarcon-Aguilara FJ, Roman-Ramos R, Perez-Gutierrez S, et al. Study of the anti-hyperglycemic effect of plants used as antidiabetics. Ethnopharmacol. 1998;61(2):101-110.

8. Wan PH, Lau J, Chalmoro TC. Metal-analysis of effect of Intensive blood glucose control on the Diabetic complication of Diabetes. Lancet. 1993;341(8856):1306-1309.

9. Robert N Frank. Diabetic Retinopathy. N Engl J Med. 2004;350:48-58.
10. Ghani NR, Khazainul Advia, Idara Kitabus Shifa YNM. pp. 322-323.

11. Kabeeruddin H, Mukhzanul Mufradat (2007).

12. Ansari MY. Munafe-ul-mufredat Aejaz publishing house. 2012.

13. CCRUM. Unani Pharmacopoeia of India. 2007.

14. Khare CP. Indian Medicinal Plants. ( $1^{\text {st }}$ edn), Springer (India) private limited, India, 2007; pp. 587.

15. Al Rowais NA. Herbal medicine in the treatment of diabetes mellitus. Saudi Med J. 2002;23(11):1327-1331.

16. Kar A, Choudhary BK, Bandyopadhyay NG. Preliminary studies on the inorganic constituents of some indigenous hypoglycaemic herbs on oral glucose tolerance test. J Ethnopharmacol. 1999;64(2):179-184.

17. Acherekar S, Satya N. Medicinal plants for diabetes. J of endocrinology. 2000;1(3):343-345.

18. Karen Sanders. Aloe Vera juice helps lowers blood sugar and cholesterol. Natural Health. 2013;365(4):122-127.

19. Rajnandan Patnaik. International journal of innovative research \& development. 2014;3(12):401-407.

20. Dey L, Attele AS, Yuan CS. Alternative therapies for type 2 diabetes. Altern Med Rev. 2002;7(1):45-58.

21. Kar A, Choudhary BK, Bandyopadhyay NG. Comparative evaluation of hypoglycaemic activity of some Indian medicinal plants in alloxan diabetic rats. J Ethnopharmacol. 2003;84(1):105-108. 